\title{
Breast Cancer Metastases of the Left Occipital Condyle Diagnosed through Extended Mastoidectomy: Case Report
}

\author{
Peter Valentin Tomazic, M.D., ${ }^{1}$ Thorsten Ropposch, M.D., ${ }^{1}$ Ulrike Nemetz, M.D., ${ }^{1}$ \\ and Christian Walch, M.D. ${ }^{1}$
}

Skull base metastases are rare conditions. Usually breast or prostate cancers are responsible primary tumors. Definite diagnosis can only be obtained through biopsies. We report the first case of breast cancer metastases into left occipital condyle, which was biopsied successfully through radical extended mastoidectomy under computer-assisted intraoperative navigation. This access proved to be feasible and safe, and enough material could be obtained for histological examination. According to the result, optimal adjuvant treatment strategies could be planned.

KEYWORDS: Extended radical mastoidectomy, computer assisted navigation, breast cancer metastases, occipital condyle, skull base

Skull base metastases frequently occur in patients suffering from breast or prostate cancer. ${ }^{1}$ Diagnosis of these metastases often is difficult due to occult growth. They mostly become symptomatic when cranial nerves are involved and palsies are seen. ${ }^{1}$ Hall et $\mathrm{al}^{2}$ reported one of the first series of breast cancer metastases in skull base in 10 patients. They reported an affection of cranial nerve $\mathrm{V}$ and VII in 60 to $70 \%$ of the patients, and no intracranial metastasis was reported. Capobianco et $\mathrm{al}^{3}$ reported a series of 11 patients suffering from an occipital condyle syndrome defined as unilateral occipital pain associated with XII nerve palsy through metastases of the skull base. Again, the most common malignancies were breast and prostate cancer. ${ }^{3}$ For definite diagnosis, biopsies must be obtained. Metastases at the occipital condyle are difficult to reach surgically due to its proximity to important neurovascular structures. To our knowledge, we report the first case of breast cancer metastases at the skull base diagnosed through a radical extended mastoidectomy.

\section{CASE REPORT}

We report the case of a 48-year-old woman who had suffered from breast cancer 7 years ago. The tumor was staged T1N1bIIM0 with an intermediate grade. The tumor was estrogen and progesterone receptor-positive. HER2 neu receptors were negative. Back then, the tumor was excised, and a unilateral axillary lymphnode dissection was performed. Adjunctive chemoand radiation therapy as well as antihormonal therapy had been applied without any complications. Follow-up controls did not reveal any recurrence for 7 years until a cranial computed tomography $(\mathrm{CT})$ scan was performed after trauma due to strong occipital tension-type headache on the left side. The CT scan revealed a tumor at

\footnotetext{
${ }^{1}$ Division of Neurootology, ENT University Hospital Graz, Auenbruggerplatz, Graz, Austria.

Address for correspondence and reprint requests: Peter Valentin Tomazic, M.D., Division of Neurootology, ENT University Hospital Graz, Auenbruggerplatz 26/28, A-8036 Graz, Austria (e-mail: peter. tomazic@medunigraz.at).

Skull Base Rep 2011;1:13-16. Copyright (C) 2011 by Thieme
}

Medical Publishers, Inc., 333 Seventh Avenue, New York, NY 10001, USA. Tel: +1(212) 584-4662.

Received: May 20, 2010. Accepted after revision: August 14, 2010. Published online: March 15, 2011.

DOI: http://dx.doi.org/10.1055/s-0031-1275245.

ISSN 2157-6971. 


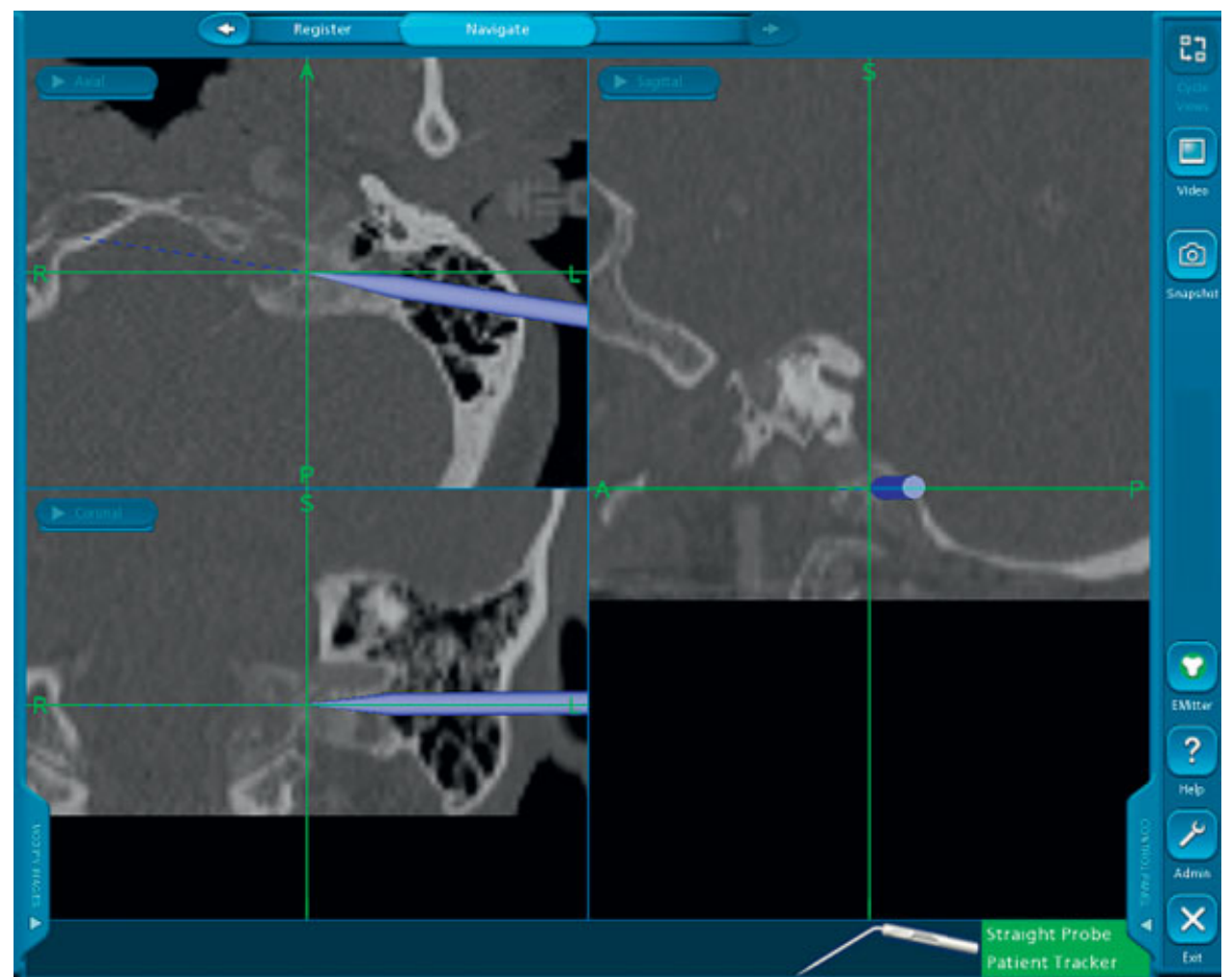

Figure 1 Intraoperative image of computer navigation with the indicated probe (blue) pointing at the lesion in left occipital condyle.

the occipital condyle on the left with topographical relation to the sigmoid sinus.

Due to the patient's history, an extended radical mastoidectomy under navigational control was performed for biopsy (Figs. 1 and 2). After all mastoid cells had been opened with the burr, the sigmoid sinus, dura of middle cranial fossa, and horizontal semicircular canal were identified as landmarks. Then, under navigational control, an access inferior to the sigmoid sinus was created, directed medially toward the left occipital condyle. The jugular bulb was identified, and caudally and medially to it, tumorlike masses were encountered destroying the bone of the condyle. Several biopsies were taken from there. Histology revealed metastases of the known breast carcinoma.

Because of the neurovascular relationships of the metastasis and its inoperability, a stereotactic radiosurgical therapy using the gamma knife was decided upon. The volume irradiated equaled $8.3 \mathrm{~cm}^{3}$ with a maximal irradiation dose of 41.8 Gy over a total period of 108.19 minutes on seven isocenters.

Postoperatively, the patient did not show any adverse effects of the therapy. Magnetic resonance imaging investigations will be performed at regular intervals.

\section{DISCUSSION}

Reports on skull base metastases of breast cancer are rare. $^{1,2,4}$ Those lesions mostly remain occult, and they remain undiagnosed until cranial nerves are involved or pain is reported. ${ }^{1,3,4}$ This case report describes metastasis in the left occipital condyle in a patient with history of breast cancer, which was discovered through a CT scan when headaches after trauma did not resolve. The patient did not have intracranial involvement or cranial nerve palsies. Because it was unclear whether the lesion in the CT scan was a metastases or posttraumatic change, an extended mastoidectomy for biopsy was performed to obtain a proper diagnosis. Another option

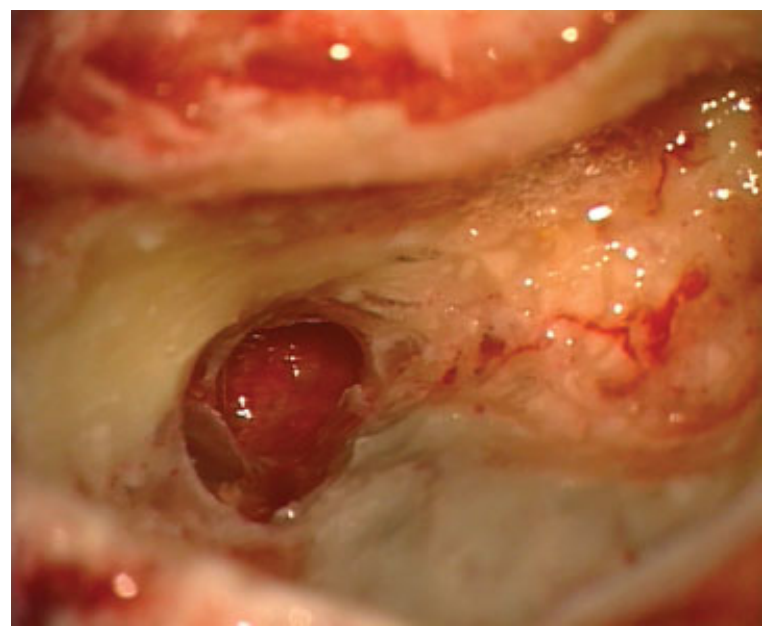

Figure 2 Intraoperative view of the canal created to make a biopsy in left occipital condyle. Around the canal, a classical radical mastoidectomy can be seen. 
would have been to perform a suboccipital craniotomy for diagnosis. As it was dubious that the lesion really was a metastasis and because of its topographical proximity to the mastoid cell system, an extended mastoidectomy was decided upon as it is less traumatic and associated with fewer comorbidities such as bone dehiscence, vascular injury, cerebrospinal fluid leak, and longer hospitalization compared to craniotomy. The use of intraoperative navigation helped to identify the lesion to gain sufficient material for histological workup.

Usually distant metastases in breast cancer in other locations than skull base lead to death. ${ }^{1}$ Skull base metastases in otherwise tumor-free patients are rare conditions. Due to localization, surgical therapy is limited. Thus, radiotherapy and chemotherapy, as well as antihormonal therapy, are the treatment of choice in a palliative setting. ${ }^{1}$ Particularly when tumor is small $(<30 \mathrm{~mm})$ and/or patients have previously been irradiated, gamma knife surgery is useful as stereotactic treatment. In this case, too, the interdisciplinary tumor conference considered the tumor inoperable under radical conditions via a craniotomy, and thus, stereotactic treatment was decided upon to provide a higher quality of life than attempted radical excision with probable postoperative craniocervical instability. Capobianco et $\mathrm{al}^{3}$ reported a series of occipital condyle syndrome, which they considered stereotypic for metastases. They recommended thorough radiological examinations of the craniocervical junction in persistent occipital pain so as to not overlook possible metastases as a differential diagnosis, especially when patients have a history of malignancy. Other reported localizations of breast cancer metastases in ENT are nasopharynx and the paranasal sinuses. ${ }^{5,6}$ In a report by Fyrmpas et al, ${ }^{6}$ breast cancer metastases in paranasal sinuses were discovered after endoscopic sinus surgery for chronic sinusitis.

This report adds to literature another case of skull base metastases in a breast cancer patient, which was accidentally diagnosed in a CT scan performed after a trauma with persistent occipital pain.

\section{CONCLUSION}

Skull base metastases of breast cancer are a rare condition. Especially patients showing cranial nerve palsy with unknown etiology or a so-called "occipital condyle syndrome" need to be carefully checked by radiological examination.

Our case demonstrates the feasibility of an extended mastoidectomy performed under computer-assisted navigation for diagnosis of metastases of the left occipital condyle. Through this approach, enough material can be harvested to gain a definite diagnosis without performing a craniotomy.

According to definite histological and immunohistochemical workup, optimum treatment strategies such as gamma knife and additional antihormonal therapies can be planned.

\section{REFERENCES}

1. Laigle-Donadey F, Taillibert S, Martin-Duverneuil N, Hildebrand J, Delattre JY. Skull-base metastases. J Neurooncol 2005; 75:63-69

2. Hall SM, Buzdar AU, Blumenschein GR. Cranial nerve palsies in metastatic breast cancer due to osseous metastasis without intracranial involvement. Cancer 1983;52:180-184

3. Capobianco DJ, Brazis PW, Rubino FA, Dalton JN. Occipital condyle syndrome. Headache 2002;42:142-146

4. Pavithran K, Doval DC, Hukku S, Jena A. Isolated hypoglossal nerve palsy due to skull base metastasis from breast cancer. Australas Radiol 2001;45:534-535

5. Saab GA, Abdul-Karim FW, Samara M. Breast carcinoma metastatic to the nasopharynx. J Laryngol Otol 1987;101: 723-725

6. Fyrmpas G, Televantou D, Papageorgiou V, Nofal F, Constantinidis J. Unsuspected breast carcinoma presenting as orbital complication of rhinosinusitis. Eur Arch Otorhinolaryngol 2008;265:979-982 